\title{
Tobacco Control joins Index Medicus and Medline
}

In April of this year, we learned from the US National Library of Medicine (NLM) that Tobacco Control was selected to be indexed and included in Index Medicus and its online counterpart, Medline, on the Library's Medical Literature Analysis and Retrieval System (Medlars). Databases in Medlars provide international access to the world's biomedical journal literature. The databases will include citations for articles in Tobacco Control that are chosen for indexing, as well as the indexing terms ("keywords") and the English abstract printed in the journal.

Tobacco Control joins a select group of journals in Medlars. About 3800 journals are currently indexed in Index Medicus/Medline, representing about $28 \%$ of the $13000-14000$ biomedical journals now being published throughout the world. Through its Literature Selection Technical Review Committee, the NLM reviews all new biomedical journals for possible inclusion in its databases. Approximately 360 unindexed journal titles are reviewed each year, and an average of $21 \%$ receive a score high enough to be selected. Currently indexed titles may also be dropped from the NLM's databases. ${ }^{12}$

The NLM's grading system includes an overall rating, which reflects scores in two major areas. The first area grades the "quality" of the journal, based on individual scores for scientific content, authors, editorial work, production, currency, and originality. The second area considers the "importance" of the journal, based on individual scores for importance to researchers, clinicians who are specialists in the field, clinicians who are not specialists in the field, educators, administrators and policy-makers, allied health professionals, students, and an international audience. On a scale of 0 (very poor) to 5 (excellent), Tobacco Control received a grade of 4.5 for overall quality. Again on a scale of 0 (not important) to 5 (very important), the journal received a grade of 4 for overall importance. In a third category- "Other comments"-it was noted that Tobacco Control "critically synthesizes and organizes knowledge in the field". The overall rating for Tobacco Control was 4.5. Currently a journal must receive an overall score of 4.0 or higher to be selected for indexing. ${ }^{2}$

Tobacco Control becomes the first journal devoted to the subject of tobacco and health to be approved for indexing in Index Medicus/Medline. This achievement is not only important for the journal and its publisher, editors, and contributors; it is also important for the field of tobacco control. In an editorial in the inaugural issue of the journal, I expressed my hope that Tobacco Control would "enhance the esteem of the movement, to help it attract a more abundant supply of educators, advocates, and researchers". ${ }^{3}$ Having a peer-reviewed journal which is now indexed in one of the world's best-known bibliographic databases goes a long way towards advancing that cause.

Indexing of the journal also helps to legitimise "the science of tobacco control". This is significant because the behavioural sciences-which include the study of tobacco use and its determinants-have often been regarded as "soft" compared with older disciplines, such as genetic, $\stackrel{+}{+}$ molecular, and other types of "basic" research. Two major areas of focus in Tobacco Control-research on policy and $\frac{\bar{\sigma}}{\bar{\omega}}$ advocacy ${ }^{4}$ - have been considered even more on the $\frac{\vec{\sigma}}{\widehat{D}}$ fringe. Indexing this journal helps to confer respect and $Q$ legitimacy to those areas of inquiry.

The candidacy of Tobacco Control for indexing was $\vec{\circ}$ strengthened by the submission of many letters of support $\overrightarrow{\vec{H}}$ from influential organisations and individuals. Endorse- $\vec{\omega}$ ment letters came from the World Health Organisation; $\vec{c}$ several federal agencies in the United States, including the or Centers for Disease Control and Prevention, the Environmental Protection Agency, the National Cancer Institute, $₫$ the National Institute of Dental Research, and the 9 National Institute on Drug Abuse; other journal editors; $\vec{c}$ and distinguished university researchers and deans. We $\subsetneq$ acknowledge their support with gratitude.

Unfortunately, the NLM will begin indexing Tobacco $\vec{\bullet}$ Control starting with volume 5 , and does not now plan to $\%$ index articles in back issues of the journal. As Lois Ann o Colaianni, executive editor of Index Medicus, explained (Letter to RM Davis, 16 May 1996):

"The National Library of Medicine normally does index the first couple of years of a new journal that is selected for indexing $\stackrel{\mathbb{D}}{\mathbb{D}}$ early in its publishing history; however, in February the General Services Administration's Board of Contract Appeals suspended the contract action under which citations and abstracts were edited and entered into Medline. This situation has resulted in a very large backlog of current material. It is not practical to think that the Library can input the earlier citations and therefore staff $\overrightarrow{0}$ are not planning to. Our major task is to input the citations to the journals we are currently indexing. Should this situation change in $\delta$ the next few months, we will resume our practice for all titles selected for indexing during this time period."

The number of biomedical journals is proliferating. As a result, researchers are relying more and more on electronic searches of the literature. This makes it all the more essential for important articles to be indexed in key 8 bibliographic databases, so they become more easily acces- $₹$

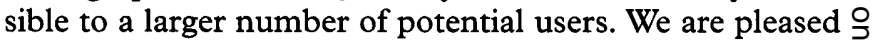
that articles in Tobacco Control will now be included in $D$ Index Medicus/Medline, but we are disappointed that articles in the first four volumes, at least for now, will not $\bar{N}$ be included. In the coming months we will approach those operating other bibliographic databases to request that $\mathrm{N}$ they too index Tobacco Control.

Editor

RONALD M DAVIS $\underset{0}{0}$

1 Journal selection for Index Medicus/MEDLINE [fact sheet]. Bethesda, $\underset{\mathbb{D}}{\stackrel{O}{\mathbb{D}}}$ Maryland: National Library of Medicine, April 1995.

2 Response to enquiries about journal selection for indexing at NLM. Bethesda, Maryland: US National Library of Medicine, undated (distributed in October 1995).

3 Davis RM. The slow growth of a movement: and finally, a journal. Tobacco Control 1992;1:1-2.

4 Chapman S. Upgrading the academic respectability of advocacy studies. Tobacco Control 1992;1:81-3.

5 Davis RM. Tobacco policy research comes of age. Tobacco Control 1995;4:6-9. 굴 